\title{
DEL GÉnero Negro a la "FICCIÓn PARANOICA": BLANCO NOCTURNO DE RICARDO PIGLIA
}

\section{FROM HARD BOILED TO "PARANOID FICTION":}

RICARDO PIGLIA'S BLANCO NOCTURNO

\begin{abstract}
Alfonso Macedo Rodríguez
Licenciado en Letras hispánicas por la Universidad Autónoma MetropolitanaIztapalapa, Maestro en Teoría literaria por la UAM-I, Doctor en Teoría literaria por la misma institución. Profesor de la Facultad de Ciencias Humanas y la Escuela de Arquitectura, Diseño gráfico y Comunicación de la Universidad La Salle Pachuca. alfonsomacedo@hotmail.com
\end{abstract}

El autor realista de novelas policiales habla de un mundo en que los gánsters pueden dirigir países: un mundo en el que un juez tiene que tiene una bodega clandestina llena del alcohol puede enviar a la cárcel a un hombre apresado con una botella de whisky encima. Es un mundo que no huele bien, pero es el mundo en el que usted vive. No es extraño que un hombre sea asesinado, pero es extraño que su muerte sea la marca de lo que hoy llamamos civilización.

RAYMOND CHANDLER, El simple arte de matar

\section{Resumen}

Este artículo analiza la transición del género negro a la llamada "ficción paranoica", concepto que Ricardo Piglia elabora para su novela Blanco nocturno. Las referencias intertextuales contribuyen a una posición estética y ética que desembocan en una crítica al sistema capitalista y la ausencia de valores morales, como la solidaridad y la justicia.

Palabras clave: Ricardo Piglia, Literatura hispanoamericana contemporánea, "ficción paranoica", novela moral, análisis intertextual.

\section{Abstract}

This paper analyzes the thriller transition to the "paranoid fiction", Ricardo Piglia's concept for his nove/ Blanco nocturno. Intertextual references contribute to aesthetic and ethical position leading to a critique of the capitalist system and the emptiness of moral values, such as solidarity and justice. 
Keywords: Ricardo Piglia, Contemporary Latin American Literature, "paranoid fiction", moral novel, intertextual analysis.

La producción literaria del escritor argentino Ricardo Piglia (1941) siempre ha mantenido un diálogo con la tradición de la alta cultura y las manifestaciones de los medios masivos de comunicación. Sus novelas, fragmentos de diario, ensayos y entrevistas han acercado esos mundos, aparentemente antagónicos e irreconciliables. Por un lado, Piglia ha creado escenas de discusión en espacios considerados tradicionalmente como de simple entretenimiento (sus conferencias de literatura transmitidas en la televisión son un ejemplo); por otro, y de manera invertida, ha colaborado en los periódicos de su país para crear nuevos vínculos entre literatura "culta" y mass media: sus ensayos de La Argentina en pedazos, que anteceden a las historietas que representan escenas clásicas de la literatura y la violencia argentinas, son otro ejemplo (Piglia, 1993).

De este modo, su obra literaria mantiene esa tensión entre los productos de la alta cultura con sus acercamientos a las manifestaciones de los medios de información. Sus novelas, nouvelles y cuentos reproducen el discurso erudito de la nota filológica ("Nombre falso" es la narración de un texto inédito de Roberto Arlt, que el personaje "Ricardo Piglia" sigue con pasión de detective), pero también navegan en las aguas de los llamados "géneros menores": la ciencia ficción, el fantástico y el policial. En gran medida, estos géneros, tan importantes en la cultura de masas, funcionan en la obra de Piglia como dispositivos intertextuales que le permiten mantener un diálogo con la tradición literaria. En este artículo, el acercamiento al género policial se llevará a cabo a través del estudio de Blanco nocturno (2010).

\section{Blanco nocturno y la tradición del género negro en Argentina}

La presencia del género policial en la narrativa de Piglia es una constante que cruza toda su obra. Su cuento "La loca y el relato del crimen" (1975), así como sus novelas Plata quemada (1997) y Blanco nocturno, lo ubican como un autor muy cercano al género ${ }^{1}$. Por eso, también en otras obras aparecen personajes que se dedican a la investigación, son detectives que persiguen textos inéditos (como el personaje "Ricardo Piglia" de la nouvelle "Nombre falso"), buscan una pista que los guíe para entender la historia argentina (Emilio Renzi en Respiración artificial) o una prueba contundente de la censura del régimen (Junior en La ciudad ausente).

Para los estudiosos del género policial, hay una división perfectamente delimitada: en su "Introducción" a El relato policial en la Argentina, Jorge B. Rivera ofrece una clasificación del género policial en cuatro subgéneros: la novela problema, "que supone el planteamiento y la develación de un enigma según procedimientos lógicos y verosímiles" (Rivera, p. 10); el relato policial de intriga o suspenso; el thriller o

${ }^{1}$ Para un estudio del primer texto policial de Piglia, cfr. el segundo capítulo de mi tesis de maestría: "La loca y el relato del crimen: ruptura e inversión del género policial" (Macedo, 2007, pp. 33-73). 
novela de acción y aventuras criminales; y la novela dura, "con su visión crítica o exasperada del orden social y del mundo del poder y del dinero" (Rivera, p. 10). Como puede apreciarse, los tres últimos subgéneros pueden confundirse con facilidad; por eso, para el presente estudio, quizá solo sea necesario establecer diferencias entre los géneros antagónicos por naturaleza: la novela policial clásica ("novela-problema"), al estilo de Edgar Allan Poe, Arthur Conan Doyle y Gilbert Keith Chesterton, y el género negro ("novela dura" para Jorge B. Rivera). El propio Ricardo Piglia distingue ambos modelos donde la gran diferencia es, probablemente, la perspectiva moral:

Si la novela policial clásica se organiza a partir del fetiche de la inteligencia pura y valora, sobre todo, la omnipotencia del pensamiento y la lógica abstracta pero imbatible de los personajes encargados de proteger la vida burguesa, en los hard-boiled norteamericanos esa función se transforma y el valor ideal pasa a ser la honestidad, la "decencia”, la incorruptibilidad (Piglia, 2005, p. 98).

Con la cita anterior, queda delineada la frontera entre ambos subgéneros policiales y, de paso, podemos empezar a penetrar en el género negro, tendencia artística más cercana a la moral porque las historias narradas reproducen, con gran realismo, los grandes problemas económicos y sociales de nuestra época. A diferencia de Borges, que introdujo a los grandes autores clásicos de las letras anglosajonas, los escritores de la "novela-problema", Ricardo Piglia se acerca a la zona no canónica, sino subversiva del género. Este acercamiento comienza, incluso, señalando: "En la historia del surgimiento y la definición del género pienso que el cuento de Hemingway Los asesinos juega el mismo papel que jugó Los crímenes de la rue Morgue de Edgar Poe con respecto a la novela de enigma" (Piglia, en Lafforgue y Rivera, pp. 61-62), en una clara oposición al género policial clásico difundido por Borges en las décadas anteriores². Su formación como lector, editor y director de la Serie Negra, en 1969, es fundamental. Ahí da a conocer, entre otras, las obras de Raymond Chandler y Dashiell Hammett (Rivera, p. 17), probablemente los autores más importantes del género en la literatura estadounidense.

Si Borges se convierte en un fiel seguidor de la novela clásica policial, Piglia, por su parte, contribuye a la difusión del género negro con su labor editorial. Años más tarde, algunos de sus textos policiales estarán mucho más cerca del género negro que de la novela-problema.

Blanco nocturno es una novela policial que ofrece una gran cantidad de guiños al lector con respecto a la tradición de la novela-problema (el asesinato de la víctima se lleva a cabo en un cuarto cerrado, y los testimonios confunden la identidad del supuesto criminal Yoshio Dazai, al igual que la confusión en la lengua del criminal según los testigos en "Los crímenes de la calle Morgue"), pero que avanza hacia las

\footnotetext{
${ }^{2}$ Para mostrar el contraste entre las preferencias literarias de Borges y Piglia, el primero, en el mismo volumen citado, declara sobre Hemingway: "Una vez Hemingway se comparó con Kipling, en quien reconocía sin embargo a un maestro. No sé cómo pudo decir semejante disparate. Hemingway, que fue medio compadre, terminó matándose porque se dio cuenta que no era un gran escritor. Esto lo salva en parte" (Lafforgue y Rivera, p. 59).
} 
convenciones del género negro (descripción de escenas sexuales, uso de narcóticos, lenguaje popular) hasta llegar a la propuesta estética y política de Piglia: la "ficción paranoica". Mediante el empleo de la cita, la alusión y otras referencias intertextuales, la novela establece un diálogo con las variantes del policial, en el contexto de las letras rioplatenses y los problemas políticos de Argentina.

La llegada de Tony Durán, ciudadano estadounidense de origen puertorriqueño, a un pueblo anónimo de la provincia de Buenos Aires, despertará en los habitantes todo tipo de conjeturas y suposiciones: no saben por qué ha ido a parar a ese pueblo olvidado, pero sí saben que llega detrás de las mellizas Belladona, Ada y Sofía, hijas de uno de los hombres más influyentes del pueblo, Cayetano Belladona.

Parte del enigma consiste en averiguar qué hace Tony en ese sitio y por qué visita al viejo Belladona en su casa. Poco a poco, el lector irá entendiendo que la relación es estrictamente económica, como ocurre con todos los relatos de la serie negra: Tony Durán es asesinado por asuntos de dinero y no por un crimen pasional, como la policía y los medios comienzan a difundir.

La historia se sitúa en marzo de 1972, en el contexto de la larga "vuelta de Perón". El país, controlado con debilidad por los militares (Romero, pp. 185-190) tras la destitución del General Juan Domingo Perón en 1955, se encontraba a la espera de un cambio de gobierno más popular y equitativo. Desde el lado económico, había comenzado la época de la especulación financiera en todo el mundo y el inicio de un sistema capitalista más abstracto e incomprensible, lo que produjo una gran devaluación económica. En este sentido, éste es el centro del relato y de la crítica al capitalismo que establece Piglia: Ios hijos de Cayetano Belladona, Lucio y Luca, habían montado una gran fábrica automotriz en los límites del pueblo; eran grandes inventores y tenían múltiples contratos con distintas firmas que pedían sus diseños. Sin embargo, la prosperidad y los proyectos terminan cuando los hermanos compran a crédito unas máquinas en Estados Unidos y de la noche a la mañana el dólar sube en la cotización, por lo que la deuda se vuelve impagable. Así queda de manifiesto en una nota del informe de Schultz, secretario de Luca:

"Más irreal era la economía y más ilusoria. Le había causado un shock el anuncio -del presidente de los EE. UU., Richard Nixon, el domingo 15 de agosto de 1971 por la noche- del fin de la convertibilidad en oro del dólar, fin del Patrón Cambio Oro [...] A partir de ese momento todo había sido, según Luca, 'una piojera' y -había estado pensando- pronto iba a empezar a dominar la especulación financiera sobre la producción material. Los banqueros iban a imponer sus normas y las operaciones abstractas iban a dominar la economía" (informe de Schultz) (Piglia, 2010, n. de la p. 232).

La aparición de Cueto, antiguo consejero de los hermanos y del viejo Belladona, es decisiva: convence a éste y a Lucio de vender el $51 \%$ de las acciones de la compañía para recibir capital y no perder la empresa, pero eso es justamente lo que ocurre cuando los nuevos socios toman el control: "el consejo de administración del directorio vota un dividendo estructural sobre el capital y así recupera su inversión 
inicial. Es lo que técnicamente se llama vaciamiento -o lavado- de una empresa (wash and wear system)" (Piglia, 2010, n. de la p. 196). Luca rompe con su hermano y su padre, la fábrica entra en quiebra y aquél se instala a vivir en su fortaleza.

Una de las características del género negro es la crítica que establece al sistema capitalista. Los nuevos socios esperan vender el espacio para crear un centro comercial o un lugar dedicado a la feria anual agrícola. Sabiéndose traicionado por Cueto, quien abandona su puesto de asesor y es nombrado fiscal del pueblo, subordinándose a los enemigos de Belladona (los nuevos socios de la fábrica) el viejo Belladona decide ayudar a Luca (Lucio había muerto poco después en un accidente carretero) para que recupere la fábrica y, en un viaje de las mellizas a Estados Unidos, consigue que Tony Durán lleve una cantidad de dinero que el viejo no había declarado y que tenía en una cuenta de ese país ${ }^{3}$. Sin embargo, ese dinero nunca llegará a su destino porque los enemigos innombrables del viejo Cayetano asesinan a Tony. El dinero, móvil del rescate de la fábrica y causa del crimen, queda incautado hasta que éste sea esclarecido. Mientras, Luca debe pagar la siguiente letra de la hipoteca. Con ese dinero, iba a salvar su proyecto personal.

Blanco nocturno es una novela dividida en dos partes: la primera se inscribe en el género negro; la segunda, mucho más breve, puede ser leída bajo el concepto de "ficción paranoica" que Piglia había abordado años atrás. En esta parte el dilema moral de los personajes, principalmente de Luca, permite una reflexión que no solo incluye la economía, sino también los actos éticos y sociales de los ciudadanos. La estructura de la novela contempla, también, tres zonas textuales totalmente diferenciadas: la narración en tercera persona por Emilio Renzi en forma de crónica; las notas a pie de página que funcionan como un subtexto que explica con mayor detalle algunos aspectos de la historia: la geografía del pueblo (dividido en clases sociales), el comienzo de la especulación financiera en tiempos del presidente estadounidense Nixon, etc.; y por último, los "suplementos" en cursivas que aparecen al final de muchos capítulos, compuestos por los diálogos entre Renzi y Sofía, y que pueden ser leídos como una interpretación de las acciones por parte de los personajes y como una contextualización para los lectores. Así, la novela ofrece distintos puntos de vista en diferentes momentos: la narración de los hechos, las notas a pie de página y los "suplementos" en cursivas que contribuyen a la búsqueda de la solución del enigma ante la muerte de Durán y el papel que juega la familia Belladona.

De acuerdo con lo anterior, en la primera parte quedan establecidos los aspectos representativos de la novela negra; simultáneamente, el lector va encontrando pistas que indican la intención del autor por inscribirse en la tradición del género en Argentina. Las referencias intertextuales permiten un juego paródico donde nuestro

\footnotetext{
${ }^{3}$ En su análisis del género negro, Piglia señala que "La relación con el dinero es la clave. Las mujeres son el lugar de pasaje” (Piglia, 2005, p. 96). En Blanco nocturno, la presencia de las mellizas, como una mujer desdoblada, parece ser un homenaje a uno de los más importantes autores del género negro en Estados Unidos, Raymond Chandler: "En realidad, las mujeres son las hijas del dinero. Habitualmente, en Chandler, son hijas de hombres poderosos y aparecen de a dos, son hermanas. Una es siempre depravada y perversa, y la otra es una suerte de doble atenuada" (Piglia, 2005, p. 93). Por otra parte, sostiene en una entrevista: "Las mellizas son mujeres malas, en el sentido de adjetivo calificativo benéfico" (García, 72). En la novela que nos ocupa, Ada, misteriosamente, está muy cercana a Cueto y parece ser la más provocativa y peligrosa. Sofía, en cambio, se hace amante ocasional de Renzi y parece esa "doble atenuada" de la que habla Piglia.
} 
escritor argentino se ubica dentro de la tradición policial del género duro a través del homenaje a autores y personajes ficcionales argentinos que lo antecedieron.

Quizá el homenaje más significativo quede representado en el comisario Croce, el personaje que se mantiene ajeno a toda ambición económica y que intenta revelar el secreto detrás del crimen de Durán. El apellido italiano remite, de antemano, al crítico literario Benedetto Croce, en una alusión pigliana a los nexos entre el detective y el ejercicio de la crítica literaria: Croce lee los signos que lo llevan a la solución del enigma. En los límites de la parodia, el narrador presenta a este personaje como un sujeto calificado por los habitantes del pueblo como "un poco tocado" (Piglia, 2010, p. 27), insobornable en sus investigaciones y lúcido, aunque situado en los límites de la demencia:

Acertó muchas veces porque parecía ver cosas que el resto de los mortales no podía ver. Por ejemplo, acusó a un hombre de haber violado a una muchacha porque lo vio salir dos veces del cine donde daban Dios se lo pague. Y el hombre realmente la había violado aunque el dato que lo llevó a incriminarlo no parecía tener sentido. Otra vez descubrió a un cuatrero porque lo vio tomar el tren a la madrugada para ir a Bolívar. Y si va a Bolívar es porque quiere vender la hacienda robada, dijo. Dicho y hecho (Piglia, 2010, p. 27).

El comisario Croce representa al investigador de las narraciones del género negro en Argentina, con un marcado antiintelectualismo, el ejercicio del sentido común y una intuición genial que lo lleva a la resolución de todos sus casos. Ubicado como rival de los representantes de la ley, en la novela aparece como un investigador incómodo para el fiscal Cueto, que busca jubilarlo porque con su investigación obstaculiza los planes de desaparecer la fábrica de Luca Belladona. Croce representa al detective criollo que solo hace su trabajo a cambio de un módico sueldo; su lugar se encuentra junto a otros célebres detectives de las letras argentinas:

¿Y qué podía hacer un policía de pueblo? Croce se estaba quedando solo. Al comisario Laurenzi, su viejo amigo, lo habían pasado a retiro y vivía en el sur. Croce se acordaba de la última vez que habían estado juntos, en un bar, en La Plata [...] Se acordaba bien, la cara flaca, el pucho que le colgaba al costado de la boca, el bigote lacio. Al loco del comisario Treviranus lo habían trasladado de la Capital a Las Flores y al poco tiempo lo habían censanteado como si él hubiera sido el culpable de la muerte de ese imbécil pesquisa amateur que se dedicó a buscar solo al asesino de Yarmolinski. Después estaba el comisario Leoni, tan amargado como todos, en la comisaría de Talpaqué (Piglia, 2010, pp. 95-96).

Esta referencia intertextual permite ubicar a Croce, personaje de Piglia, en la línea de los detectives famosos de la literatura argentina: el primero, Laurenzi, pertenece a la segunda etapa de la literatura policial de Rodolfo Walsh; el segundo, Treviranus, es un personaje secundario de "La muerte y la brújula" de Borges; por último, Leoni, que vuelve a ser mencionado en páginas posteriores porque desde Talpaqué llama 
a Croce para darle una pista del crimen, es un personaje de Adolfo Pérez Zelaschi (Braceras y Leytour, pp. 17-21).

A través de la amistad de estos personajes, Piglia establece una línea genealógica que empieza con la aparición del comisario criollo en Argentina, de acuerdo con Elena Braceras y Cristina Leytour: se trata del detective Erik Lönnrot de "La muerte y la brújula" de Borges. El inicio del cuento cobra un sentido irónico que pasa inadvertido hasta el final cuando se descubre que este investigador ha caído en una trampa mortal: "Es verdad que Erik Lönnrot no logró impedir el último crimen, pero es indiscutible que lo previó" (Borges, p. 153). Treviranus, partidario del sentido común en las investigaciones criminales, se opone al método de aquél, que intenta descifrar los crímenes mediante la lectura de los textos sagrados judíos: "Bruscamente bibliófilo o hebraísta, ordenó que le hicieran un paquete con los libros del muerto" (Borges, pp. 157-157). La ironía borgiana está presente en este enunciado, pues Lönnrot, que desprecia el azar en el crimen de Yarmolinsky, opta por una investigación erudita que lo lleva a la muerte, pues su gran enemigo, el asesino Red Scharlach, lee en el diario su línea de investigación y monta una serie de crímenes para hacer que aquél llegue a su muerte. Por eso, Treviranus es trasladado fuera de la capital y después cesado de su cargo.

Por su parte, Leoni, personaje de Pérez Zelaschi, al igual que Laurenzi y Croce, representa al detective sencillo. "Los tipos inteligentes sólo hacen macanas, guerras, revoluciones, libros, teorías raras, crímenes... No sirven para nada, pero se creen superiores" (Pérez Zelaschi citado por Braceras y Leytour, p. 21).

De los tres comisarios, Laurenzi es quizá el más parecido a Croce. Como ya dije, es un personaje de Rodolfo Walsh, el escritor argentino desaparecido por la Junta Militar en 1977. Walsh comenzó su carrera literaria con Variaciones en rojo, tres cuentos policiales bajo el estilo de la novela-problema. En estos cuentos, el detective es el editor Daniel Hernández, de filiación intelectual, quien resuelve los crímenes. Sin embargo, estos ejercicios racionales y esteticistas cambiaron a partir de un acontecimiento político: en 1956, el ejército reprimió una manifestación a favor del general Perón (exiliado un año antes debido a un golpe de Estado) y asesinó a muchos de sus simpatizantes. Walsh, que esa noche estaba jugando ajedrez, conoció el testimonio de algunos sobrevivientes y poco después comenzó la redacción de Operación masacre, su novela de Non fiction que indaga en estos acontecimientos. De este modo, se acercó a la literatura de mayor tendencia social. Después, fueron apareciendo sus nuevos relatos policiales, pero no con el erudito Daniel Hernández como detective (quien ahora se convierte en una suerte de Watson, en su función de narrador intradiegético), sino con Laurenzi, el comisario que resuelve todos los crímenes gracias a su inteligencia y sentido común.

Croce, gran amigo de Laurenzi, representa también la postura peronista; queda marginado (como Walsh y el padre de Ricardo Piglia, que comparte con Walsh la filiación política y el fracaso político) cuando se organiza y fracasa la revuelta a favor de Perón: 
Croce había nacido y se había criado en la zona, se había hecho policía en la época del primer peronismo, y desde entonces estaba en el cargo -salvo el interregno después de la revolución del general Valle en el 56-. Los días previos al levantamiento Croce había estado alzando las comisarías de la zona, pero cuando supo que la rebelión había fracasado anduvo como muerto por los campos hablando solo y sin dormir y cuando lo encontraron ya era otro. El comisario había encanecido de la noche a la mañana en 1956, al enterarse de que los militares habían fusilado a los obreros que se habían alzado para pedir el regreso de Perón (Piglia, 2010, p. 26).

La filiación Croce-Laurenzi es clara: se trata de una estrategia intertextual que permite un vínculo estético-político entre Walsh y Piglia $^{4}$. Es la visión de los perdedores que escriben la historia. Así, la literatura se convierte en una práctica de supervivencia y en un documento -como la crónica- que revela lo que el Estado intenta ocultar.

Este marcado antiintelectualismo en los cuatro comisarios está señalado desde el epígrafe de la novela; se trata de una cita de Louis-Ferdinand Celine, autor francés de novelas policiales admiradas por Juan Carlos Onetti -uno de los escritores a los que Piglia también rinde homenaje en Blanco nocturno-: "La experiencia es una lámpara tenue que sólo ilumina a quien la sostiene". Así, se anuncia la transición de la novela negra a la ficción paranoica, ya que Croce, por medio de su experiencia, puede descifrar los signos que anuncian el fracaso de la moral y el triunfo de los promotores del capitalismo en el pueblo.

Precisamente Croce, comisario de la vieja guardia argentina, capaz de resolver cualquier crimen, representa ese modelo de la literatura negra estadounidense que apuesta todo a la práctica, lejos de cualquier erudición. En uno de sus ensayos sobre el género policial, Piglia apunta: "la práctica parece ser el único criterio de verdad: el investigador se lanza, ciegamente, al encuentro de los hechos, se deja llevar por los acontecimientos y su investigación produce, fatalmente, nuevos crímenes" (Piglia, 2005, p. 97). Sin decir nada sobre su teoría del crimen de Durán, Croce hace publicar la fotografía de un jockey, el Chino Arce, autor material del crimen, quien había aceptado el cargo para comprar el caballo con el que había corrido y triunfado muchas veces. Poco después, Croce recibe la llamada de Leoni desde Talpaqué, en la que refiere el suicidio del jockey. Con esta base, Croce da a conocer los resultados de su investigación: el crimen de Durán se realizó para detener el dinero que Durán había traído de Estados Unidos de una cuenta que el viejo Belladona no había declarado; ante la posibilidad de que Luca pague la hipoteca de la fábrica, los socios -cuyos nombres nunca se dicen y la única cara visible es Cueto- mandan matar a Durán. Así, quien había sido acusado del crimen, el trabajador del hotel donde Tony se hospedaba, el japonés Yoshio Dazai, podría

\footnotetext{
${ }^{4}$ En su conferencia "Tres propuestas para el próximo milenio (y cinco dificultades)", el autor de Respiración artificial resume la vida literaria y política de Walsh: "Comenzó escribiendo cuentos policiales a la Borges y escribió uno de los grandes textos de literatura documental de Hispanoamérica: Operación masacre; paralelamente escribió una extraordinaria serie de relatos cortos y por fin desde la resistencia clandestina a la dictadura militar, escribió y distribuyó el 24 de marzo de 1977 ese texto único que se llama Carta abierta de un escritor a la Junta Militar, que es una diatriba concisa y lúcida. Fue asesinado al día siguiente en una emboscada que le tendió un grupo de tareas de la Escuela de Mecánica de la Armada. Su casa fue allanada y sus manuscritos fueron secuestrados y destruidos por la dictadura" (Piglia, 2001a, pp. 14-15).
} 
ser absuelto. Sin embargo, Cueto declara que Croce está loco y Yoshio sigue en la cárcel ${ }^{5}$.

\section{La "ficción paranoica"}

La gran diferencia entre la novela-problema del género policial y el género negro es la perspectiva social del segundo. La crítica dirigida al sistema económico y a la desigualdad social, junto con la corrupción de las clases hegemónicas, es una constante. En el género negro, los crímenes son perpetrados por dinero; en cambio, en la sofisticada novela de enigma, muchas veces el crimen obedece a otras razones: vanidad, envidia, deseo, etc. El triunfo de la razón, además, hace que el misterio se esclarezca y el asesino sea castigado. La novela-problema es casi matemática. Su antítesis es, en este sentido, la novela negra:

Por un lado, los thrillers vienen a narrar lo que excluye y censura la novela policial clásica. Ya no hay misterio alguno en la causalidad: asesinatos, robos, estafas, extorsiones, la cadena siempre es económica. El dinero que legisla la moral y sostiene la ley es la única razón de estos relatos donde todo se paga (Piglia, 2005, p. 96).

Liberada de la rigurosa trama y de "la lógica imbatible" (Piglia, 2001b, p. 60) del detective (un intelectual como el refinado Auguste Dupin y el exquisito Sherlock Holmes), la novela negra navega por la corrupción, el crimen brutal y el asesinato por intereses económicos. Como bien sostiene Piglia, el detective de la novela policial clásica es el encargado de "proteger la vida burguesa" (Piglia, 2005, p. 98) y eso lo diferencia del detective de la serie negra, quien con su incorruptibilidad en cuestiones monetarias se muestra invariable: así se convierte en un modelo a seguir: "En las virtudes del individuo que lucha solo y por dinero contra el mal, el thriller encuentra su utopía" (Piglia, 2005, p. 98).

Croce, personaje solitario, viudo, ajeno a cualquier institución social, ha resuelto el crimen, pero no hay posibilidad de probar su teoría. Además, el fiscal Cueto se ha encargado de hacer correr el rumor de que ha enloquecido ${ }^{6}$. Por falta de elementos, Yoshio será condenado.

La trampa en que Cueto y la gente que conspira contra los Belladona hace que los errores de Cayetano salgan a la luz: para ayudar a su hijo, ingresa al país miles de dólares de forma clandestina a través de Tony Durán, el contacto que sus hijas habían Ilevado al pueblo desde Estados Unidos. La única posibilidad de que Yoshio

\footnotetext{
${ }^{5}$ La condición marginal de los personajes es fundamental en el género negro: Yoshio, de origen japonés y nacido en Argentina, es homosexual, lo que de inmediato funciona para que los testigos del crimen lo señalen como asesino. El Chino Arce, de complexión pequeña al igual que Yoshio, se hizo pasar por éste para crear la versión del crimen pasional. La gente había sugerido cierta relación amorosa entre Durán y el japonés. Además, Tony Durán también es un ciudadano marginal: de origen puertorriqueño, apoyó la causa separatista de su país contra los Estados Unidos. Su condición de ciudadano del tercer mundo (traspatio de Estados Unidos), así como los rumores de su relación con Yoshio, funcionan para cerrar el caso por un crimen de amor.

${ }^{6}$ De algún modo, Croce comprueba esta hipótesis por su tendencia al autismo, sus largas y voluntarias estancias en el manicomio local y su detención, debido a una crisis nerviosa, cuando repartía volantes en la calle en los que aseguraba que Yoshio era inocente. Su personalidad, que se encuentra en los umbrales de la demencia, también lo hacen ver las cosas con más lucidez que el resto de los habitantes del pueblo.
} 
sea absuelto tiene que ver, nuevamente, con el dinero decomisado. Ahí es donde la novela toma el sentido moral que se venía perfilando desde las primeras líneas y aun desde el epígrafe de Celine: Luca debe rendir testimonio para intentar acceder al dinero y pagar la hipoteca:

Cueto desplazó el centro de la cuestión y planteó el dilema con extrema claridad jurídica. Si Luca -en su condición de principal demandante- aceptaba que Yoshio Dazai había matado a Durán, la acusación seguía su curso, el caso quedaba resuelto y el dinero iba a su legítimo dueño, el señor Belladona. Si, en cambio, Belladona no firmaba ese acuerdo y mantenía su demanda, el caso seguía abierto y el dinero permanecería incautado durante años porque nadie iba a poder cerrar ese caso y las pruebas no pueden ser retiradas de los tribunales mientras la causa esté abierta. Perfecto. La decisión de Luca cerraba el caso ya que se suponía que Durán había venido a traerle ese dinero (Piglia, 2010, p. 278).

Luca, de quien nos dice el narrador que estaba atado a una idea fija (salvar la compañía a cualquier precio) tendrá que tomar una decisión moral. El dilema es ético, por lo tanto. Uno de los recursos literarios que la novela ostenta es la del desplazamiento en la identidad del asesino: si en la novela clásica el detective señala al culpable para que el crimen no quede impune y se restablezca el orden (un orden burgués, como apunta el escritor argentino), en el género negro, a pesar de los hallazgos de Croce (que demuestran que el crimen no es pasional, sino económico y especulativo, como el negocio que harán los socios con los terrenos de la fábrica automotriz), la autoridad es sobornada por la plutocracia local y la responsabilidad y el poder de la culpabilidad del supuesto criminal recae en otro personaje, un ciudadano obsesionado con su proyecto, que no había previsto el papel de juez que se le estaba asignando: en realidad, se le soborna para aceptar la hipótesis del crimen amoroso. Reprimir el deseo de ayudar a un inocente y anteponer la moral a un proyecto individual es el dilema de Luca en el juicio. Croce no había asistido -como gran lector de los signos de la realidad, ya sabía lo que iba a ocurrir- y preveé un desenlace trágico. Su perro, símbolo de la amistad y la solidaridad, y que visitaba muchas veces a Luca en la fábrica, sí aparece una vez que el juicio legal ha concluido:

Y entonces lo más extraordinario fue que cuando llegó a la vereda apareció el cuzco, el perro de Croce, medio ladeado como siempre, que al verlo salir a la luz del sol se le fue encima y le ladró, y le mostró los dientes como si fuera a morderlo, casi sin fuerza pero con odio, el pelaje amarillo tenso como su cuerpo, y esos ladridos fueron lo único que Luca recibió ese día (Piglia, 2010, p. 281).

En este sentido, Blanco nocturno es una novela cercana al realismo social del género negro donde los verdaderos criminales no son identificados ni sentenciados, 
por lo que se condena a un inocente (un ser marginado socialmente: mucamo, oriental, homosexual ${ }^{7}$ ):

No es cierto que se pueda restablecer el orden, no es cierto que el crimen siempre se resuelve... No hay ninguna lógica. Luchamos para restablecer las causas y deducir los efectos, pero nunca podemos conocer la red completa de las intrigas [...] Las novelas policiales resuelven con elegancia o con brutalidad los crímenes para que los lectores se queden tranquilos (Piglia, 2010, pp. 283284).

De este modo, la instauración de la "ficción paranoica" en la literatura y la sociedad obliga a los individuos a pelear en solitario, sin alianzas con los integrantes de todas las clases sociales, ante un sistema capitalista disfrazado de democrático pero profundamente represivo: "Habría que inventar un nuevo género policial, la ficción paranoica. Todos son sospechosos, todos se sienten perseguidos. El criminal ya no es un individuo aislado, sino una gavilla que tiene el poder absoluto" (Piglia, 2010, p. 284), reflexiona Renzi. El sistema filosófico occidental se resquebraja ante el dominio del capitalismo y el liberalismo. Justamente, el epígrafe que abre otra novela de Piglia, Plata quemada, es una cita de Bertolt Brecht: "¿Qué es robar un banco comparado con fundarlo?" (Piglia, 2008) El problema económico, entonces, siempre es moral.

\section{Fuentes de Consulta}

- BORGES, Jorge Luis (2000). Ficciones, Madrid: Alianza Editorial.

- BRACERAS, Elena, y Cristina Leytour (selección, introducción, notas y propuestas de trabajo) (2002). Cuentos con detectives y comisarios, Buenos Aires: Ediciones Colihue.

- GARCÍA, Gastón (2011). "La experiencia artística es una pausa de la lógica de la realidad. Entrevista a Ricardo Piglia”, Letras libres, 147, 68-73.

- LAFFORGUE, Jorge, y Jorge B. Rivera (1977). Asesinos de papel. Una introducción: historia, testimonios y antología de la narrativa policial en la Argentina, Buenos Aires: Calicanto Editorial.

- MACEDO RODRÍGUEZ, Alfonso (2007). De la crítica a la ficción y de la ficción a la crítica: una lectura sobre la poética de Ricardo Piglia (tesis de maestría), México: Universidad Autónoma Metropolitana-Iztapalapa.

- PIGLIA, Ricardo (2010). Blanco nocturno, Barcelona: Anagrama (Narrativas hispánicas, 476).

\footnotetext{
7 "La loca y el relato del crimen", el cuento policial publicado por Piglia en 1975, ofrece una trama policial que se adelanta treinta y cinco años a Blanco nocturno: ahí, un tratante de blancas (padrote o cafishio) asesina a una prostituta. Como lo protegen desde arriba, culpan al amante de la mujer asesinada. Una loca es testigo del crimen pero no puede hablar coherentemente. Renzi, periodista de El Mundo, descifra el mensaje psicótico de la loca mediante un método lingüístico. Sin embargo, el director del diario lo censura: "hace treinta años que estoy metido en este negocio y sé una cosa: no hay que buscarse problemas con la policía. Si ellos te dicen que lo mató la Virgen María, vos escribís que lo mató la Virgen María" (Piglia, 1999, p. 162).
} 


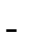

(2001b). Crítica y ficción, Barcelona: Anagrama (Argumentos, 267).

-

- ---------- (2005). El último lector, Barcelona: Anagrama (Narrativas hispánicas, 376).

- ---------- (1993). La Argentina en pedazos, Buenos Aires: Ediciones de la Urraca (Col. Fierro).

- --------- (2008). Plata quemada, Barcelona: Anagrama (Narrativas hispánicas, 291).

- --- (2001a). Tres propuestas para el próximo milenio (y cinco dificultades), México-Buenos Aires: FCE (C. P., 607).

- RIVERA, Jorge B. (1986) El relato policial en la Argentina. Antología crítica, Buenos Aires: Editorial Universitaria de Buenos Aires.

- ROMERO, Luis Alberto (2004). Breve historia contemporánea de la Argentina, Buenos Aires: FCE. 